\title{
A Preliminary Study of the Ink Painting Technique in The Dream of Red Mansions
}

\author{
Wen Zhang ${ }^{1} \&$ Xiaoming Yang ${ }^{1}$ \\ ${ }^{1}$ College of Humanities, Donghua University, Songjiang, Shanghai, China \\ Correspondence: Xiaoming Yang, College of Humanities, Donghua University, Songjiang, Shanghai, 201620, \\ China. E-mail: ynide@sina.com
}

Received: April 15, 2020

doi:10.5539/ass.v16n5p144
Online Published: April 30, 2020

URL: https://doi.org/10.5539/ass.v16n5p144

Foudation item: The year 2018-2019 Fundamental Research Funds for the Central Universities and Graduate Student Innovation Fund of Donghua University "Research on the development of sizing technology in China" (Project No., CUSF-DH-D-2019105) stage of achievements.

\begin{abstract}
As we all know, a batch of excellent note novels emerged in Ming and Qing Dynasties. Among these books, "The Dream of the Red Chamber" is undoubtedly the best work of ancient Chinese novels, and the description of clothing is also very accurate and unique. "A dream of Red Mansions" has many accurate descriptions of clothing and textile. There are 173 entries about clothing, involving as many as 50 entries in textile and clothing. Mr. Zhou Ruchang even called Cao Xueqin "the expert of clothing display". It provides rich materials for the research of the history of textile science and technology. Among them, the ink painting technique also occupies an important position, and has a profound significance for the development of textile and clothing in the Ming and Qing Dynasties.
\end{abstract}

Keywords: the Dream of Red Mansions, the ink painting technique, Ming and Qing Dynasties

\section{The Importance of Studying the Costume of Novels in Ming and Qing Dynasties}

The dream of Red Mansions plays an important role in Chinese classical literature. It is not only highly accomplished in literature and art, but also occupies a very important position in the history of clothing and textile technology. The costumes described in The Dream of Red Mansions have distinct characteristics: rich, vivid and accurate. Now we have not obvious time discrimination on the clothing described in The Dream of Red Mansions. In the early Qing Dynasty, because of the adoption of Jin Zhijun's proposal, the proposal of "ten from and ten not from" was implemented, including "men from and women from" and "old from and young from". In The Dream of Red Mansions, women's clothing is mainly described, that is to say, most of the women's clothing mentioned in the novel is Han nationality clothing. Jia Baoyu, another character with more ink on his clothes, was not an adult in the first 80 chapters, which was in line with the principle of "the old never follow the young". Therefore, we can make the following conclusion: most of the description of clothing in The Dream of Red Mansions belongs to Chinese traditional clothes, Hanfu.

The revival of modern Chinese clothing is obvious to all. In many universities nowadays, Hanfu societies are set up by students themselves out of their hobbies. With the efforts of these young people, Hanfu can be said to be reborn. Today, with the development of e-commerce, there are a large number of successful businesses on the e-commerce platforms. Hanfu is no longer a traditional dress that we can only get a glimpse of in the ancient literature, but a regular dress that we can wear everyday. In carrying forward traditional culture, we have a very arduous task. Of course, the restoration of Hanfu is on the one hand, wearing the clothes of the ancients and thinking about the aspirations of the ancients are our ultimate goal for the restoration of Hanfu.

The main impression in the novel The Dream of Red Mansions is that the description of clothing is very flexible. Only the general outline is outlined in the description of specific clothing details. When reading such a novel, the reader's imagination space for the main clothing of the characters in the novel is very large. However, because of its flexible writing style, dream of Red Mansions shows us the actual development of people's clothing and very important textile technology in Ming and Qing Dynasties. As mentioned above, the dream of Red Mansions does 
not specify the specific dynasties, and there is no clear mark to infer the background of the dynasties. However, the creation of art is from life, so before we explore the art of playing ink in the book, we come to the following conclusion: Cao Xueqin's book may not be a specific description of Ming and Qing costumes, but to a certain extent, it deeply reflects that women in the Ming and Qing Dynasties And the description of minor men's clothing.

\section{Ink Painting Technique in The Dream of Red Mansions}

Elastic ink is to use the technology of elastic ink to print small black flowers on light colored silk and satin. In the first 80 chapters of the dream of Red Mansions, ink painting appears more frequently. From Baoyu's socks to azalea's skirts to Xiren's baggage at home, there are shadows of ink painting technique technology. It can be seen from this that the technology of ink painting is a very popular printing and dyeing technology in Ming and Qing Dynasties.

The third chapter: "Daiyu thought this was the place of Jia Zheng. Seeing the three chairs on the Kang and the half old ink painting technique chair, Daiyu sat down on the chair."

This is the first time that the ink painting technique appears in The Dream of Red Mansions. From the perspective of Daiyu, I saw the ink painting technique chair on the decoration when I visited Mrs. Wang. The explanation of "chair burden" in modern Chinese dictionary is "chair cover made of cotton, satin and so on". The elastic ink here is used to make chair cover, not to explain its material, but only to explain the technology, which proves that the elastic ink at that time is a very representative description, and also can be seen in the background of the wide spread of the elastic ink technology at that time. Here we have a bold conclusion: the technology of elastic ink is a very popular textile technology in the Ming and Qing Dynasties.

The third chapter: "The bottom half of the pants are made of loose flowers and brocade silk. They are elastic black socks with brocade edges and big red shoes with thick soles."

This is Jia Baoyu's first appearance. He changed into his first relatively formal dress and came to his mother's place to have dinner in his homely clothes. Since it's home-made clothes, the materials used for clothes are not very treasured. However, in order to highlight the rich atmosphere of Jia's mansion, brocade is inlaid on the edge of the elastic ink socks. The elastic ink is originally plain color, and the socks with plain color as the main body are inlaid with more luxurious brocade, which also reflects that the elastic ink is actually a process that can match multiple materials and colors. We can draw the second conclusion through the description here: the elastic ink is a very flexible textile technology.

The seventeenth chapter: "There are 120 curtains of different colors, silk and silk, and 80 curtains were made yesterday."

This is the curtain curtain in the Grand View Garden that Jia's house is going to welcome yuan Chun. The curtains and curtains in the novel are of different shapes and colors. Some Jia Mu went to Daiyu's place and asked Sister Feng for "soft smoke" to make a tent to hang by herself. Some of them also went to the spring exploration place to "embroider the gauze of flowers and insects on both sides". Imagine that in the green tent, the patterns of flowers and insects are embroidered on both sides, which is quite unique. But Baochai's place only hung a "green gauze curtain" because it is too simple, Jia Mu got it The criticism, and people changed the "ink painting white silk tent.". It can be seen from this that the requirements for curtain in Jia's residence are very high. The elastic ink here is put together with "make-up Python embroidering pile and tapestry".

The fifty first chapter: "Looking at the package again, I had only one package in the water red silk with ink and silk, which only contained two half old cotton padded jackets and leather coats

This is to write that Sister Feng sent clothes to Xi Ren and Xing Xiuyan. As a modifier, the application material of elastic ink here, Aya, appeared for the first time. "Zhengzitong: Department": "those who weave plain are called Qi, and those whose light is like a mirror with flowers are called Ling." Just imagine that there are already damask patterns on the surface and black florets printed with elastic ink technology, which not only makes the original patterns filled with color, but also makes the ink patterns printed with elastic ink technology have a concave convex texture, and all these wonderful collocations are applied to a package Wang Xifeng sent to Xi Ren and Xing Xiuyan, from which we can see the luxury of daily life of Jia Fu. From this description we can get the conclusion four: the elastic ink technology is a kind of textile technology which can be applied to a variety of fabrics, with the most damask.

The fifty seventh chapter: "I saw him in a thin cotton padded jacket with elastic ink and silk, and only a vest with green satin on the outside." 
The dress of Zijuan is very elegant and unique. Daiyu is a lady of boudoir with strong poetic atmosphere. Her maid, Zijuan, should be called "poetry maid" here. In a dream of Red Mansions, women who take elegance as the main tone always see the shadow of ink painting technique and related textile technology more or less. The thin cotton padded jacket made of elastic ink and silk is an example. Here we can infer another characteristic of ink painting technique: elegant and unique.

The 63rd time: "Baoyu is only wearing a small red cotton padded jacket, under which green silk is playing in black pants, with loose trouser legs, and leaning on a new pillow with jade gauze in rose and peony petals of various colors."

The elastic ink here is matched with the silk to make the pants of Baoyu. There is also a very important sign "loose trouser legs", indicating that Leggings are needed at other times, which makes the vague Dynasty of a dream of Red Mansions more controversial. In my opinion, although there is a custom of Leggings in Manchu, the custom of Leggings is not only the custom of Manchu. It is one-sided to conclude that all the costumes in a dream of Red Mansions are the products of the Qing Dynasty. The breeches here are consistent with the seasons at that time, which proves that the elastic ink technology can be used not only in spring and summer, but also in autumn and winter. It is worth mentioning that there is a shot of Baoyu's pants in the TV series of Hongloumeng of the eighth and seventh editions. The color is consistent, but no ink is used. It can be said that it is a small pity.

Chapter 109th: "A white silk skirt in light ink is tied under the waist... "

Here is a description of Miaoyu's clothes. The upper body is paddy field clothes, and the lower body is white silk skirt painted in light ink. The white silk skirt here does not use the technology of elastic ink, but uses the technology of light ink painting, which is more precious and personalized than elastic ink. Light ink painting can be said to be an extension of ink painting. It not only retains the elegance and uniqueness of ink painting technology, but also is more delicate and precious, and more caters to the psychology of the upper class society. This shows that the development of elastic ink in Ming and Qing Dynasties has been very extensive, enough to develop other textile printing and dyeing processes on this basis.

\section{The Controversy Over Ink Painting Technique}

At the end of the article "female workers' Embroidery" in teacher Deng Yunxiang's "the customs of Red Mansions" there is such an introduction:

There are also "ink painting technique", the third is about Baoyu clothes, there are "ink painting technique socks with brocade edges", the seventeenth is about the preparation of table drapery and chair drapery in Daguanyuan, there are "120 curtains of different colors of silk and silk". What is "playing ink", in short, is the brocade with patterns made of ink colored silk and white silk.

There is an important premise for the ink painting technique here, that is, the ink painting technique of the tapestry mentioned in the article can only be evolved on the basis of the tapestry, so the ink painting technique here seems to be linked with the tapestry technology, which has the characteristics related to the tapestry invisibly. The people's Literature Publishing House, 1973, in its annotation of a dream of Red Mansions, called the ink painting technique "a line or simple pattern decorated with black lines and sodium" (p. 190). Wu and Yue once thought in Kuocangshan's love and hatred record that "the black line" was sandwiched between the fingers to form a line or a simple pattern of decoration. "

Mr. Bao Mingxin's point of view is different. In the supplement to the history of ancient Chinese costume, he believed that "the ink painting technique is a kind of printed silk fabric popular in the Qing Dynasty, and its production technology belongs to the category of blow dyeing." In proving his point of view, Mr. Zhang cited the example of ancient and modern book integration. In volume 681, there are the following records in the Suzhou mansion. The ink painting technique is "spraying five colors on plain silk and mistaking it into flower and bird palace brocade" with a blowpipe. When using blowpipe to blow ink, you can use natural flowers, leaves, etc. to place them on the silk fabric lightly. Most of the silk fabrics are of damask type. Because of the covering of leaves and petals, the silk fabric presents the shape of leaves and petals. You can also use various forms of paper-cut or hollowed out materials to replace leaves or petals. Mr. Zhang also mentioned that ink can not only be used to make skirts, but also to make socks and curtains.

Based on the research of several people, we can see that in fact, ink blowing is to use blowpipe to blow ink on blank silk fabric through hollow or natural materials, rather than black and white lines meet to form a pattern. However, for the premised ink drawing process, for example, whether the "tapestry ink drawing" mentioned by Mr. Deng Yunxiang is a pattern formed by combining black and white lines, it needs to be analyzed in detail. 


\section{The Influence of Playing Ink on Ming and Qing Costumes}

The biggest influence of the ink painting technique is probably the ink painting technique skirt popular among women in the Qing Dynasty.

Compared with the Ming Dynasty, the dress of the Han women in Qing Dynasty did not change much. Even the Manchu women in the palace could wear Han clothes in their daily life. Different from the Han men, the costumes of the Han women in the Qing Dynasty retained the characteristics of the Ming Dynasty to a great extent. For example, the well-known Fengwei skirt was handed down from the Ming Dynasty, but it is a kind of more gorgeous costume. It is necessary to cut the silk and satin into long strips and then embroider the patterns on each one, and inlay the gold thread on each silk and satin edge. The production is complicated and the raw materials are expensive. In view of the productivity level at that time, For the promotion of the clothing is not very beneficial. Compared with the elastic ink skirt, it only needs to cover the petals, leaves or paper-cut on the plain cloth, and then ink-jet can be completed. It can be said that the raw materials are cheap and easy to get, the process is simple and easy to operate, and it is a very understandable thing to be popular. In addition, the shape of the tan Mo skirt is vivid, and the color is elegant and unique, which is accepted by the majority of women.

Mr. Zhou Xibao mentioned in the history of ancient Chinese costume that "later there was a move to play ink, or" ink flower skirt ", which was made by playing ink with different colors. It was elegant and tasteful." Mr. Huang Nengfu also put the Tanmo skirt and Yuehua skirt in one entry in the general history of Chinese clothing. Generally speaking, there are two reasons: first, the elastic ink technology always uses smooth textile materials as the bottom, while Yuehua skirt uses satin as the raw material, which meets the demand of elastic ink technology; second, whether Yuehua skirt is directly woven from Yuehua satin or is made by pigment spray dyeing or in doubt, if it is made by pigment spray dyeing, it is similar to the production process of elastic ink skirt.

\section{References}

Bao, M. X. (1984). On the history of ancient Chinese Costume. China Textile Press.

Cao, X. Q. (1986). The Dream of Red Mansion. People's Literature Press.

Deng, Y. X. (2004). On the customs of The Dream of Red Mansion. Hebei Education Press.

Huang, N. F. (2007). General history of Chinese clothing. China Textile Press.

Ji, X. Y. (2012). Appreciation of clothes in The Dream of Red Mansion. Zhejiang University Press.

$\mathrm{Xu}, \mathrm{X}$. (2001). Chinese and foreign women's dress culture. China Textile Press.

Zhou, X. B. (1984). History of ancient Chinese Costume. China Drama Press.

\section{Copyrights}

Copyright for this article is retained by the author(s), with first publication rights granted to the journal.

This is an open-access article distributed under the terms and conditions of the Creative Commons Attribution license (http://creativecommons.org/licenses/by/4.0/). 